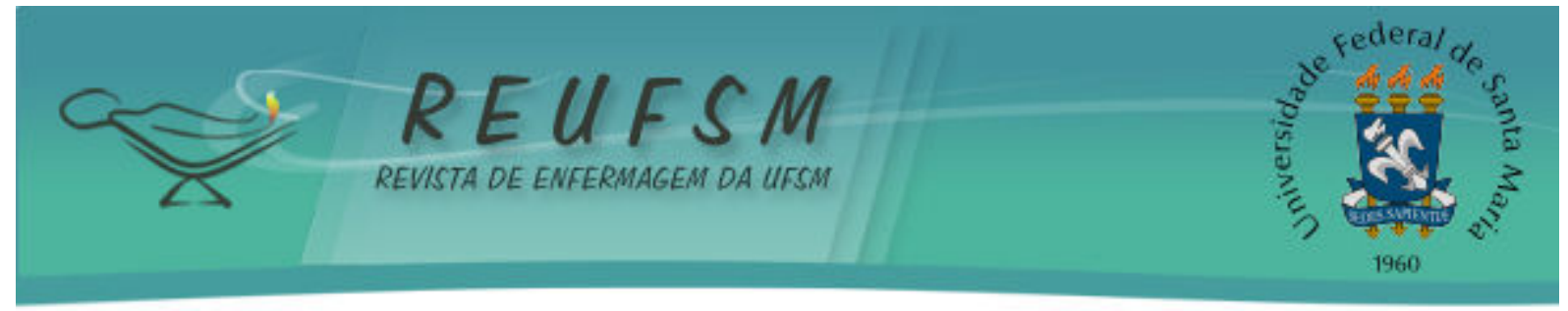

ARTIGO ORIGINAL

\title{
CARACTERIZAÇÃO DAS MULHERES AGREDIDAS EM UMA ZONA URBANA LOCALIZADA EM UMA REGIÃO DE FRONTEIRA
}

\section{CHARACTERIZATION OF WOMEN BATTERED IN A URBAN ZONE LOCATED IN A REGION OF THE BORDER}

\section{CARACTERIZACIÓN DE MUJERES ATENTADAS EN UMA ZONA URBANA UBICADA EM UNA REGIÓN DE FRONTERA}

\author{
Marcia Adriana Poll ${ }^{1}$ \\ Terezinha Weiller Heck ${ }^{2}$ \\ Barbara Letícia Dudel Mayer ${ }^{3}$ \\ Tatiane Angélica Phelipini Borges ${ }^{4}$ \\ Kelen Fabiana da Silva ${ }^{5}$ \\ Diana Baumgart ${ }^{6}$
}

Doi: $10.5902 / 2179769211042$

RESUMO: Objetivo: conhecer o perfil das mulheres agredidas em uma zona urbana localizada em uma região de fronteira do estado do Rio Grande do Sul, Brasil. Método: pesquisa quantitativa, descritiva, desenvolvida em Pronto Socorro, com 68 vítimas no período de janeiro a junho de 2013. A coleta foi por meio dos registros das fichas ambulatoriais, analisadas pelo programa StatisticPackage for Social Sciences. Resultados: a faixa etária com maior prevalência foi entre 20 e 29 anos, na maioria dos registros não constavam o agente agressor, seguidas do cônjuge. Os motivos de atendimento foram as agressões de ordem física. Entre as morbidades destacaram-se as lesões cortantes, seguidas de um encaminhamento à terapia intensiva e um óbito. Conclusões: ressalta-se a importância de aprimorar a busca dos casos de violência contra a mulher, da rede de atendimento, da realização dos registros,além de apontar a incipiência de estudos em áreas de fronteiras.

Descritores: Violência contra a mulher; Assistência à saúde; Emergências; Políticas públicas.

ABSTRACT: Aim: to know the profile of battered women in a west border region of Rio Grande do Sul, Brazil. Method: quantitative descriptive research, developed in Emergency Care, with 68 victims in the period January to June, 2013. The collection was through the records of the Outpatient chips, analyzed by the Statistical Package for Social Sciences.

\footnotetext{
1 Enfermeira, Mestre em Enfermagem PPGEnf /FURG. Professora Assistente do Curso de Enfermagem da Universidade Federal do Pampa-UNIPAMPA. Uruguaiana, RS, Brasil. Email: adripoll@hotmail.com

2 Enfermeira, Doutora em Enfermagem em Saúde Pública PPGEnf/USP. Professora adjunta do Curso de Enfermagem da Universidade Federal de Santa Maria-UFSM. Santa Maria, RS, Brasil. Email: weiller2@hotmail.com

3 Enfermeira, Mestranda em Enfermagem - PPGEnf/UFSM. Santa Maria, RS, Brasil. Email: barbaraldmayer@gmail.com

${ }^{4}$ Acadêmica do Curso de Enfermagem da Universidade Federal do Pampa (UNIPAMPA). Bolsista do projeto PROEXT 2013 - Programa de Extensão Universitária MEC/SESu. Uruguaiana, RS, Brasil. Email:tphelipini@hotmail.com

${ }_{5}$ Acadêmica do Curso de Enfermagem da Universidade Federal do Pampa (UNIPAMPA). Bolsista do projeto PROEXT 2013 - Programa de Extensão Universitária MEC/SESu. Uruguaiana, RS, Brasil. E-mail: kelen.fsilva@hotmail.com

${ }^{6}$ Acadêmica do Curso de Enfermagem da Universidade Federal do Pampa (UNIPAMPA). Bolsista do projeto PROEXT 2013 - Programa de Extensão Universitária MEC/SESu. Uruguaiana, RS, Brasil. E-mail: diana_baumgart@hotmail.com
} 


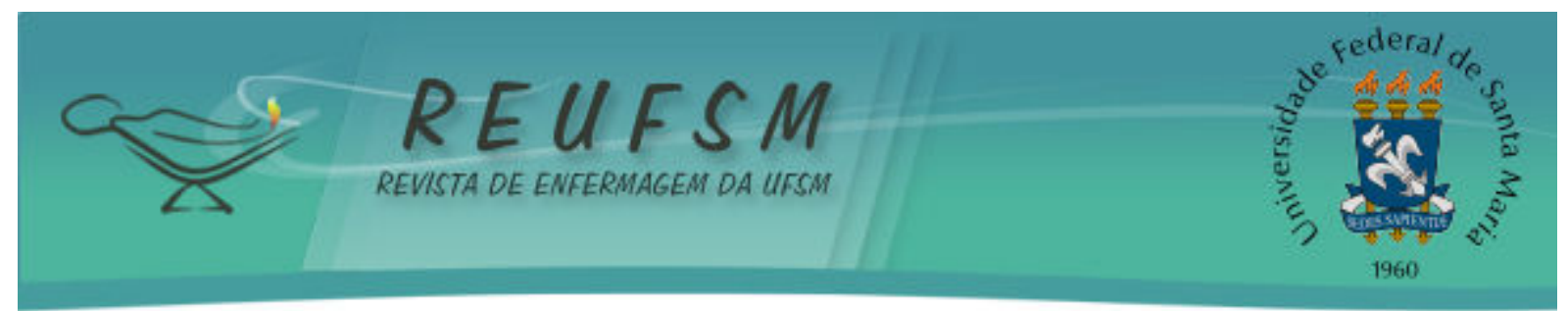

Results: the most prevalent age was between 20 and 29 years, most of the records were not in the offending agent, followed by the spouse. The reasons were the attendance of physical aggression. Among morbidities sharp injuries stood out, followed by a referral to intensive therapy and one death. Conclusions: we emphasize the importance of improving the search for cases of violence against women, customer service network, pay attention to the realization of the records and point out the incipience of studies in frontier areas.

Descriptors: Violence against women; Delivery of health care;Emergencies; Public policies.

RESUMEN: Objetivo: conocer el perfil de las mujeres agredidas en una zona urbana situada en una región de frontera del estado del Rio Grande do Sul, Brasil. Método: investigación cuantitativa, descriptiva, desarrollada en el Atendimiento de Urgencia, con 68 víctimas en el período de enero/junio de 2013. La recopilación fue mediante registros de fichas de atención ambulatoria, analizados por el programa StatisticPackagefor Social Sciences. Resultados: la edad con mayor predominio fue entre 20 y 29 años, la mayoría de los registros no constaban el sujeto agresor, seguidas de cónyuge. Los motivos de atendimiento fueron las agresiones de orden física. Entre las morbilidades se destacan las lesiones cortantes, seguidas de un direccionamiento a la terapia intensiva y un fallecimiento. Conclusiones: se destaca la importancia de mejorar la búsqueda de casos de violencia contra la mujer, el servicio de atendimiento, la realización de registros, además de señalar estudios iniciales en áreas de fronteras.

Descriptores: Violencia contra la mujer; Asistencia a la salud; Urgencias médicas; Políticas públicas.

\section{INTRODUÇÃO}

A violência é um evento de conceito complexo, que pode apresentar diferentes sentidos, podendo ser expressa através da agressão física, do abuso sexual, da violência psicológica e violência institucional. ${ }^{1}$ Vista como o emprego proposital da força física ou do poder contra outra pessoa, um grupo de pessoas e/ou uma comunidade ou contra si próprio, que resulta ou pode ocasionar lesão, morte, deficiência, dano psicológico, ou privação da liberdade. ${ }^{2-3} \hat{E}$ um problema social que incide diretamente no direito à vida, à liberdade e à dignidade humana. ${ }^{4}$ Além de não distinguir indivíduos quanto a cor, raça ou condição social, atinge todas as classes, gêneros e gerações, ultrapassando fronteiras, etnias, culturas e ideologias políticas. ${ }^{3}$

Porém, existem grupos sociais mais vulneráveis a este fenômeno. No Brasil, dentre os grupos mais atingidos pela violência, destacam-se: os jovens, os idosos e as mulheres. Sendo que a agressão contra a mulher constitui-se em preocupação atual tanto no âmbito da saúde pública como dos direitos humanos, pois atinge as mulheres no mundo todo e nas diversas faixas etárias do seu ciclo vital, provocando sérios prejuízos à sua saúde e ao desenvolvimento psicossocial. ${ }^{5}$

Ao longo dos anos, a mulher carregou o estigma de sujeito com potencialidades reduzidas frente ao homem. Tendo como base, questões construídas culturalmente pela sociedade, as quais deliberam os papéis que esses atores sociais devem assumir, de ser homem e o de ser mulher, quem agride e quem é agredido. ${ }^{6-8}$

Ao longo da história, vários foram os movimentos de enfrentamento da violência contra a mulher por parte da sociedade, os quais se traduziram nas atuais políticas públicas, legislações e conferências que tratam dessa temática como uma ação penal, que derroga os direitos humanos do gênero feminino. ${ }^{8}$ Todavia, décadas depois de movimentos feministas e de implementação de políticas públicas e de legislação punitiva, vivencia-se 


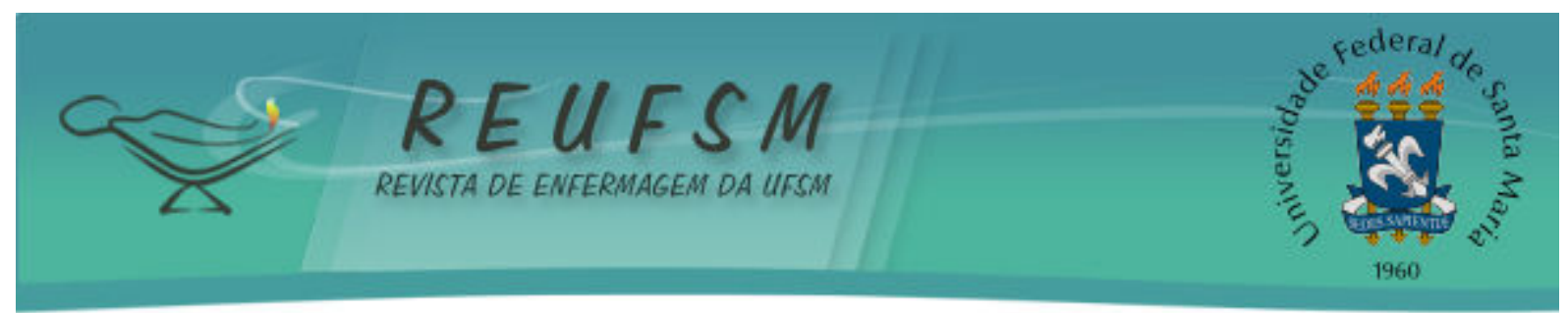

diariamente a permanência da exposição dessas vítimas a agressões interpessoais, emocionais ou psicológicas, ao abuso sexual e, sobretudo, a convívio com companheiros agressivos. Tais eventos acontecem, na maioria das vezes, no recinto doméstico e ainda continuam cercados pelo medo, que envolve o ato de denunciar, de sentir e vivenciar a exposição social, a dor física e psicológica. ${ }^{7}$

Os dados epidemiológicos evidenciam a magnitude do fenômeno, pois são importantes as proporções que a violência contra a mulher vem assumindo no Brasil, a cada dois minutos, cinco vítimas são agredidas. ${ }^{9}$ Apesar de a violência ser um fenômeno mundial, poucos países possuem legislação específica de proteção à mulher.

A Lei 11.340 - Maria da Penha, sancionada em 2006, é reconhecida pela Organização das Nações Unidas (ONU) como uma das três melhores legislações do mundo no enfrentamento à violência contra a mulher. Assim, essa Lei representa uma possibilidade concreta para que se possa produzir modificação nos indicadores de impunidade vividos em nosso país. Por meio dela, mulheres em situação de violência ganharam proteção fortalecendo em parte sua autonomia e conquista de seus direitos. A Lei Maria da Penha busca criar meios de atendimento humanizado às mulheres, agregando valores de direitos humanos à política pública e contribuindo assim, para educar toda a sociedade. ${ }^{10-11}$

Em consonância com esse novo cenário, em 2008, o Governo Federal Brasileiro lançou o Plano Nacional de Políticas para as Mulheres, com o objetivo de promover o enfrentamento de todas as formas de violência e prover atendimento específico e qualificado à sua saúde. O Ministério da Saúde (MS) tem proposto medidas para disponibilizar atendimento efetivo, integral e processual às mulheres agredidas a partir da atenção básica, por ser essa, a porta preferencial para o atendimento no sistema público de saúde, incluindo as Unidades Básicas de Saúde (UBS) e a Estratégia Saúde da Família (ESF). ${ }^{12}$

Nas últimas décadas, houve, no Brasil, um crescente aumento das instituições que atendem mulheres, adolescentes e meninas em situação de violência. A sociedade e o poder público mostram-se preocupados com o problema, e a rede de serviços tem se expandido substancialmente. Foram criadas Delegacias de Defesa da Mulher, Casas Abrigo, Serviços de Atendimento à Violência Sexual, Centros de Referência, organizações governamentais e não governamentais atuantes em diversos setores. Esses recursos de atendimento possuem culturas institucionais variadas, e buscam adequar o atendimento com profissionais de saberes e fazeres distintos e, por vezes, conflitantes, acerca do problema da violência contra mulher. ${ }^{13}$

Mesmo diante de legislações específicas que resguardam os direitos das mulheres agredidas, em que na maioria dos casos, a vítima conhece o agressor, ou seja, a violência ocorre dentro dos relacionamentos familiares ou por parceiro íntimos, muitas vezes, é de difícil averiguação, não sendo denunciada publicamente, uma vez que os casos em que há a denúncia pública são escassos. Em razão de a mulher optar por não realizar a denúncia da agressão, por medo de retaliação por parte do agressor, ou ainda pela dificuldade dos serviços em reconhecer e diagnosticar a violência. ${ }^{14-15}$

Diante do exposto, o presente estudo tem como questão norteadora: Qual é o perfil das mulheres agredidas em um município de fronteira? Assim, o objetivo desta pesquisa é conhecer o perfil das mulheres agredidas em uma zona urbana localizada em uma região de fronteira do estado do Rio Grande do Sul, Brasil.

A relevância desse estudo está na possibilidade de investigar as situações de violência visando entender como esse fenômeno vem ocorrendo, frente aos dados epidemiológicos, aos fatores condicionantes da violência e as estruturas de redes especializadas voltadas ao atendimento das mulheres agredidas. Para assim, contribuir na construção de políticas públicas que direcionem intervenções e estratégias focalizando as mulheres vítimas de violência em uma região de fronteira. 


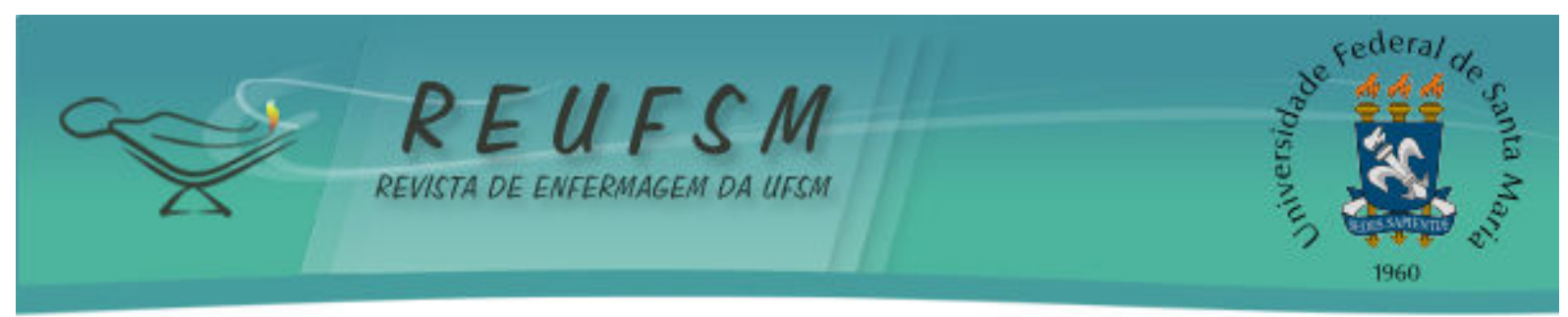

O Brasil possui uma Faixa de Fronteira extensa, tradicionalmente tratada como local de isolamento que se configura hoje como uma região de baixo desenvolvimento socioeconômico, marcada por profundas iniquidades e desigualdade regional que contribuem para o baixo desempenho econômico local,além de promover um ciclo de degradação social que, dentre outros reflexos, têm implicado em mortes precoces, violação dos direito humanos e violência contra grupos vulneráveis, como as mulheres, as crianças e adultos jovens. ${ }^{16}$

\section{MÉTODO}

Trata-se de uma pesquisa de abordagem quantitativa descritiva com delineamento documental, vinculada a um projeto guarda-chuva denominado"Perfil dos usuários atendidos por causas externas em uma unidade de Pronto Socorrode um município da região da fronteira oeste do Rio Grande do Sul".

O estudo foi desenvolvido na área vermelha do Pronto Socorro de um hospital filantrópico, geral regional de alta complexidade localizado em um município da região da fronteira oeste.A população geral do projeto guarda- chuva compreendeu 3.144 vítimas acometidas por causas externas atendidas no período de 01 de janeiro a 30 de junho de 2013. Porém, a população desse estudo foram as mulheres agredidas, compreendendo um total de 68 sujeitos.

Os critérios de inclusão dos sujeitos no estudo guarda-chuva envolveramtodos aqueles que se enquadraram dentro da classificação para causas externas de morbidade e mortalidade (V01-Y98) do código internacional das doenças (CID) 10 capítulo XX. Já os fatores de exclusão compreenderam todos os demais sujeitos atendidos na área vermelha do Pronto Socorro acometidos por outras situações de emergência, ou ainda vítimas de causas externas, mas, que ingressaram no setor de emergência por outra porta de entrada que não a área vermelha, como por exemplo, sujeitos que passaram pelo setor de triagem e foram encaminhados à área amarela, ou diretamente ao traumatologista.

Os dados foram coletados de forma retrospectiva a partir de análise dos registros das Fichas de Atendimento Ambulatoriais (FAA). Para coleta das informações utilizou-se um roteiro elaborado que continha questões como sexo, idade, cidade de procedência, data e horário de atendimento, motivo do atendimento, morbidade ocasionada pela causa externa e desfecho do caso, o qual serviu para busca direcionada de informações relevantes à pesquisa. A coleta de dados ocorreu diariamente no período disponibilizado pela instituição ou conforme acordado entre os responsáveis pela instituição coparticipante e responsável pelo Serviço de Arquivo Médico e Estatística (SAME).

Os dados foram digitados, tabulados e armazenados em Planilha Eletrônica Excel ${ }^{\circledR}$ para o processamento. Para análise, utilizou-se o programa StatisticPackage for Social Sciences (SPSS $\AA$ ), versão 21.0, ambos em plataforma Windows ${ }^{\circledR}$. Para análise dos dados, utilizou-se a estatística descritiva, a fim de apresentar os resultados no formato de tabelas por meio de frequências absolutas e porcentagens.

Para a realização dessa pesquisa, foi respeitado o sigilo, a privacidade e os preceitos éticos conforme defende a Resolução Número 466, de 12 de dezembro de 2012, de Ética em Pesquisa envolvendo Seres Humanos, do Conselho Nacional de Saúde, Ministério da Saúde. ${ }^{17}$ Desta forma, o estudo teve início após aprovação pelo Comitê de Ética em Pesquisa (CEP) Universidade Federal do Pampa - UNIPAMPA, conforme o número de protocolo CAAE $n^{\circ}$ 04010912.9.0000.5323 - Parecer 123.629, com data de aprovação do projeto de pesquisa no CEP em 17/10/2012. Em conjunto com a aprovação do diretor do Hospital Geral domunicípio da fronteira oeste do Rio Grande do Sul, por meio da assinatura do Termo de Autorização da Instituição Coparticipante. 


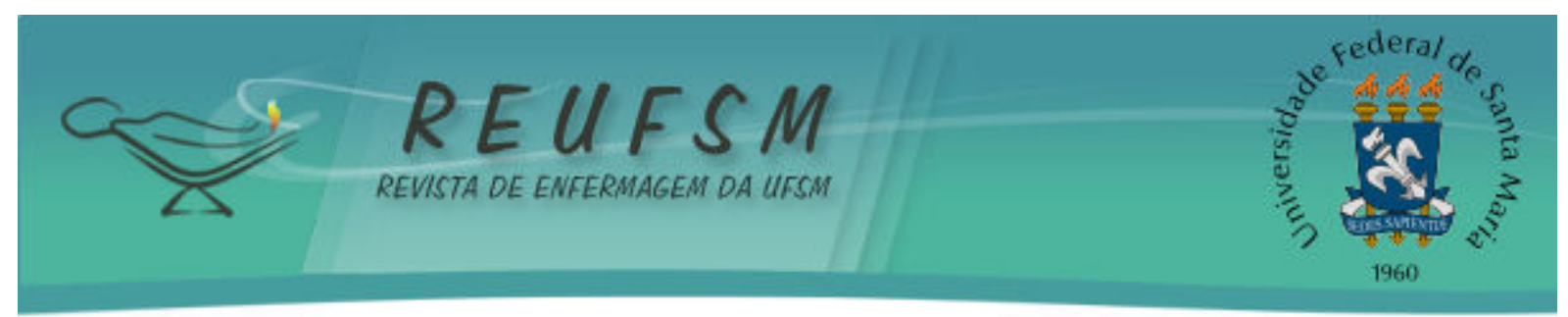

\section{RESULTADOS E DISCUSSÃO}

Dentre os 3.144 atendimentos por causas externas no Pronto Socorro, 68 casos foram de mulheres agredidas, mostrando que essas são apenas as que necessitaram buscar o serviço na área vermelha para o atendimento clínico voltado a lesões corporais, deixadas pelo agente agressor. Entretanto, pode-se pressupor que o número de vítimas seja maior, se considerarmos que muitas não procuram o serviço de atendimento quando sofrem algum tipo de agressão, e que outras nem relatam ter sofrido tal evento, procurando o serviço de saúde por outras queixas, mascarando o real problema. Além disso, existe falha na investigação no momento do atendimento e nos registros dos casos por parte dos profissionais de saúde ao não "saber" ou "querer" identificar essas vítimas. ${ }^{5}$

A falta de investigação por parte da equipe de saúde no momento do atendimento às mulheres agredidas, seja em Unidades Básicas de Saúde ou no serviço de Pronto Socorro, faz com que os profissionais percam a oportunidade de intervir de alguma forma sobre esse evento. ${ }^{5}$ Nesse sentido, é de fundamental importância que os serviços de saúde estejam preparados para identificar situações de violência sofrida pelas vítimas de agressões para que as primeiras medidas de atenção e cuidado possam ser tomadas de forma especializada e acolhedora. Além do eficaz registro e notificação dos casos, a fim de contribuir para o diagnóstico epidemiológico desse agravo.

Quanto à idade das vítimas, essas encontram-se entre os quatro e 76 anos, apresentando a maior prevalência dos 20 aos 29 anos, com 19 casos $(27,94 \%)$, seguido pela faixa etária dos 40 aos 49 anos, 15 casos (20,59\%). Pode-se associar a esse resultado a vulnerabilidade somada ao enfrentamento de situações à qual essas vítimas frequentemente submetem-se nessa faixa etária específica. ${ }^{15}$ Quanto ao agente agressor, a maioria dos casos foram registrados sem constar essa informação, seguidas do agente agressor, o cônjuge, o que pode ser observado por meio da Tabela 1.

Tabela 1 - Agente agressor das vítimas acometidas por violência atendidas em um Pronto Socorro de um Hospital, no período de janeiro a junho de 2013.

\begin{tabular}{ccc}
\hline Agressor & Frequência & Porcentual \\
\hline Não consta & 42 & $61,76 \%$ \\
Cônjuge & 16 & $23,53 \%$ \\
Vizinho & 3 & $4,41 \%$ \\
Filho & 2 & $2,94 \%$ \\
Mãe & 2 & $2,94 \%$ \\
Assaltante & 1 & $1,47 \%$ \\
Familiar & 1 & $1,47 \%$ \\
Irmão & 1 & $1,47 \%$ \\
Total & 68 & $100,00 \%$ \\
\hline
\end{tabular}

Fonte: banco de dados da pesquisa "Perfil dos usuários atendidos por causas externas em uma unidade de pronto socorro de um município da região da fronteira oeste do Rio Grande do Sul"

A não constatação do agente agressor denuncia que ainda muitas mulheres vítimas de violência não relatam quem é o autor da agressão por medo, ou porque ficam inibidas em falar, pois estariam expondo a própria família, além da existência do vínculo pessoal e afetivo. Além disso, muitas situações são consideradas comuns para a sociedade e por isso aceitáveis e não reconhecidas como violência. Como ocorre no caso da violência sexual, a qual boa parte das vítimas cede ao desejo do companheiro para não contrariá-lo, e por entenderem que é seu dever, como esposa, na relação marido e mulher. ${ }^{18}$

Já quanto ao agressor ser o cônjuge, confirma-se que a violência contra a mulher é geralmente praticada na própria residência, tendo o parceiro íntimo como principal agente 


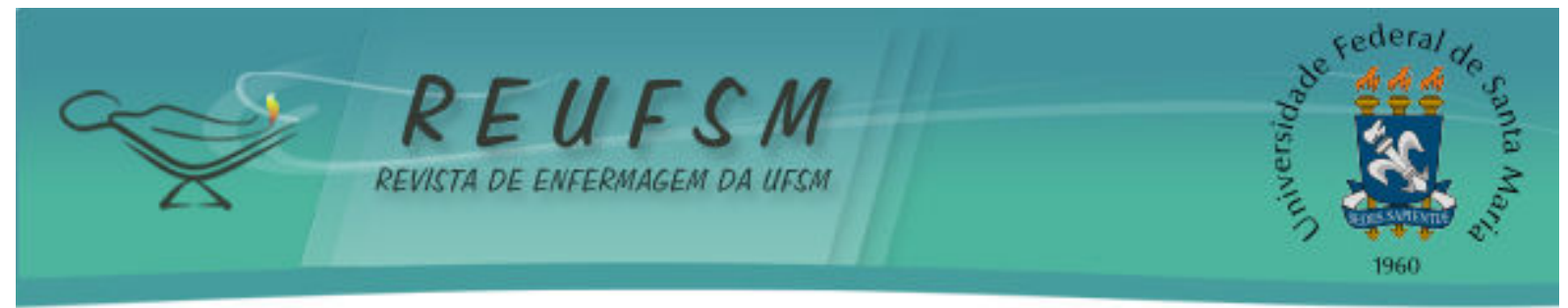

na maioria dos casos. ${ }^{5,17} \mathrm{~A}$ agressão por parceiro íntimo é uma das principais formas de violência de gênero em todo o mundo, sendo responsável por cerca de $80 \%$ dos casos. ${ }^{19-20}$

Em relação aos dias da semana em que ocorreram as agressões contra a mulher, o domingo e o sábado foram os dias de maior prevalência em relação aos demais dias, conforme demonstrado na Tabela 2.

Tabela 2 - Dias da semana que ocorreram violência contra as mulheres atendidas em um Pronto Socorro de um Hospital, no período de janeiro a junho de 2013.

\begin{tabular}{ccc}
\hline Dia da Semana & Frequência & Porcentual \\
\hline Domingo & 14 & $20,59 \%$ \\
Sábado & 13 & $19,12 \%$ \\
Sexta-feira & 10 & $14,71 \%$ \\
Terça-feira & 9 & $13,24 \%$ \\
Segunda-feira & 9 & $13,24 \%$ \\
Quinta-feira & 9 & $13,24 \%$ \\
Quarta-feira & 4 & $5,88 \%$ \\
Total & 68 & $\mathbf{1 0 0 , 0 0 \%}$ \\
\hline
\end{tabular}

Fonte: banco de dados da pesquisa "Perfil dos usuários atendidos por causas externas em uma unidade de pronto socorro de um município da região da fronteira oeste do Rio Grande do Sul"

Em relação aos horários de maior incidência de atendimentos, prevaleceu das 19:00 às 00:59 horas (44,12\%), seguido pelo horário entre 01:00 e 06:59 horas $(25 \%)$. Quanto ao motivo de atendimento das vítimas, identificou-se, que a maioria das mulheres, sofreu agressões de ordem física (espancamentos), seguidos de ferimentos por arma branca (FAB), conforme Tabela 3.

Tabela 3 - Motivo do atendimento às vítimas de violência contra a mulher atendidas em um Pronto Socorro de um Hospital, no período de janeiro a junho de 2013.

\begin{tabular}{ccc}
\hline Motivo do Atendimento & Frequência & Porcentual \\
\hline Agressão Física & 61 & $89,71 \%$ \\
FAB & 7 & $10,29 \%$ \\
Total & 68 & $100,00 \%$ \\
\hline
\end{tabular}

Fonte: banco de dados da pesquisa "Perfil dos usuários atendidos por causas externas em uma unidade de pronto socorro de um município da região da fronteira oeste do Rio Grande do Sul"

Desta forma, a presente pesquisa mostra que a violência se restringiu à agressão física a qual demandou um atendimento médico, tendo, portanto, essas mulheres buscado a unidade de Pronto Socorro, basicamente em decorrência de problemas advindos de lesões geradas a partir de atos violentos deferidos pelo agente agressor normalmente do sexo masculino, reforçada a questão de gênero. ${ }^{6-8}$

Entre as morbidades resultantes das agressões físicas, em maior quantidade apresentam-se as lesões cortantes, com 24 casos, representando $(29,41 \%)$, seguidas das demais lesões conforme demonstra Tabela 4. 


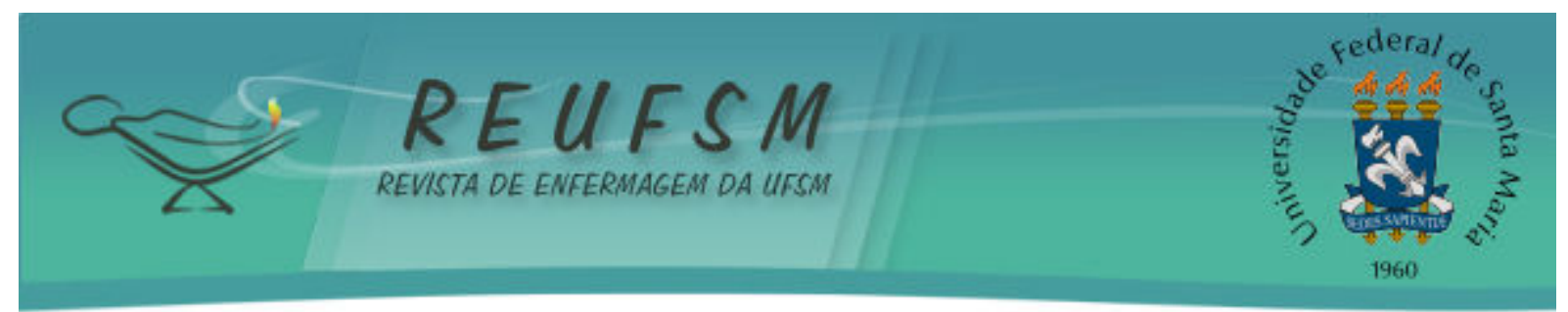

Tabela 4 - Morbidades decorrentes da violência contra as mulheres atendidas em um Pronto Socorro de um Hospital, período de janeiro a junho de 2013.

\begin{tabular}{ccc}
\hline Morbidade & Frequência & Porcentual \\
\hline Lesão Cortante & 24 & $35,29 \%$ \\
Escoriações & 13 & $19,12 \%$ \\
Não consta & 12 & $17,65 \%$ \\
Trauma & 10 & $14,71 \%$ \\
Hematoma & 5 & $7,35 \%$ \\
Algia & 4 & $5,88 \%$ \\
Total & 68 & $100,00 \%$ \\
\hline
\end{tabular}

Fonte: banco de dados da pesquisa "Perfil dos usuários atendidos por causas externas em uma unidade de pronto socorro de um município da região da fronteira oeste do Rio Grande do Sul"

Quanto aos encaminhamentos das vítimas de agressão, em 54 casos $(79,42 \%)$ não constava na ficha de atendimento para onde essa vítima foi encaminhada. Assim, é importante salientar que o monitoramento da violência contra a mulher no setor da saúde no Brasil, se dá a partir dos sistemas de informação existentes relacionados à mortalidade e à morbidade hospitalar das internações via Sistema Único de Saúde (SUS), e através da notificação compulsória da agressão contra a mulher, por meio do Sistema de Informação de Agravos de Notificação (SINAN). ${ }^{6,21}$

Portanto, a identificação de casos de agressão contra a mulher, por meiodos dados epidemiológicos das vítimas, levantados durante o atendimento no setor saúde alimentam o SINAN. Sua utilização permite a realização da caracterização da ocorrência de um evento na população, de modo a fornecer subsídios para identificar as causas dos agravos de notificação compulsória contribuindo para diagnosticar a realidade epidemiológica de cada região, voltado a diversos tipos de notificações, dentre elas a de violência contra a mulher. ${ }^{21}$

A Ficha Individual de Notificação (FIN) é um instrumento de investigação de agravos que possibilita a identificação da origem e mecanismos desse agravo, essa é preenchida quando existe a ocorrência de um problema de saúde de notificação compulsória, como ocorre nos casos de violência contra a mulher, de acordo com o decreto- Lei $n^{\circ} 5.099$ de 03/06/2004, Lei $n^{\circ} 10.778 / 2003$. Após seu preenchimento a FIN é encaminhada aos serviços responsáveis pela vigilância epidemiológica das Secretarias Municipais, essas repassam semanalmente os arquivos em meio magnético para as Secretarias Estaduais de Saúde (SES), alimentando dessa forma o sistema. ${ }^{21}$

Entretanto, além da averiguação do evento ou da suspeita do mesmo, bem como da notificação dos casos, faz-se necessário, sobretudo, haver comunicação entre os serviços de saúde e os demais setores de atenção à vítima agredida, como Casas/abrigos, Centros de Referência e Reabilitação, Delegacias especializadas, Secretaria de Políticas para as Mulheres, Secretarias de Saúde, para que se possa ter um mapa geral da violência, bem como, um atendimento de qualidade e um encaminhamentoadequado aos serviços oferecidos pela rede de atendimento à mulher.

Outro fator importante a ser destacado é a atenção especial na construção e consolidação da rede de atendimento à mulher em regiões de fronteira, porque nelas, convivem cotidianamente sistemas políticos, monetários, de segurança e de proteção social diferentes; além do intenso fluxos de produtos, serviços e pessoas, o que vem intensificar a geração de tensões e desafios para os sistemas de saúde, exigindo políticas específicas direcionadas à garantia do direito universal à saúde direcionadas a populações de uma forma geral, mas principalmente a grupos vulneráveis, dentre eles as mulheres. ${ }^{16}$

0 fortalecimento da referência e contra referência do setor saúde, é outro ponto importante que se faz necessário,pois após o atendimento inicial a essas vítimas de agressão no setor terciário - Pronto Socorro, o acolhimento e acompanhamento dessas 


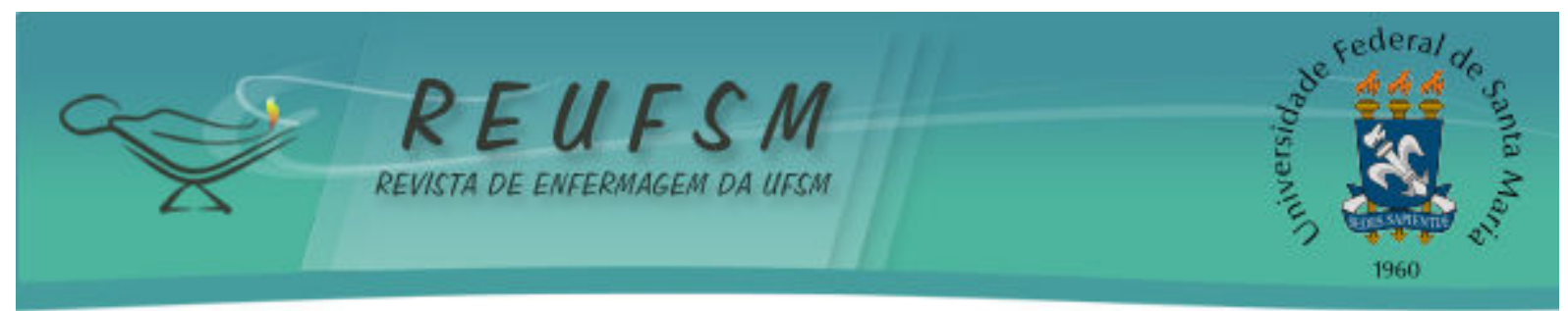

mulheres por parte do serviço de atenção básica torna-se essencial, visto que elas passaram por uma situação traumática, estão fragilizadas e necessitam de apoio da equipe de saúde para superar esse trauma. ${ }^{22}$

A Unidade Básica de Saúde (UBS) e Estratégia de Saúde da Família (ESF) demonstram ser a referência para essas mulheres, por estarem mais próximas e inseridas na comunidade, fazendo parte do contexto social dessas vítimas. Sendo, portanto um dos locais onde, necessita-se, encontrar uma equipe multiprofissional qualificada para prestar a assistência de acompanhamento necessária a esse tipo de evento, além de trabalhar em conjunto com os demais elos da rede de atendimento à mulher. ${ }^{22}$

Porém muitos profissionais da saúde desconhecem o fluxo de funcionamento e ou a existência da estrutura da rede de atendimento à mulher, bem como não reconhecem como parte de seu trabalho e/ou recursos necessários para intervir sobre esse problema de saúde, a fim de assistir as vítimas que vivenciam ou vivenciaram situação de violência. ${ }^{5,23}$

Para tanto, torna-se necessário que haja a promoção de capacitações dos profissionais de saúde em todos os níveis de atenção para conhecer as formas de violência, as normas técnicas e protocolos de assistência às vítimas, como se dá o encaminhamento aos serviços de apoio existentes na rede de atendimento à mulher. ${ }^{21}$ Bem como, necessitam estarem habilitados ao atendimento, sensíveis ao problema e com postura acolhedora, para assim, poder avaliar os sinais e sintomas, com o finalidade de prevenir e tratar as suas consequências.

Mas, para que a rede de atendimento às mulheres que vivenciam a violência funcione de forma a acolher e respaldar seus anseios e necessidades, é necessário que haja o cuidado para que não se resumam a pontos de triagem e/ou somente encaminhamentos, mas que, de fato, atuem de maneira integralizada e resolutiva. Pois não basta apenas criála é necessário que ela funcione, tornando-se um ponto verdadeiro de referência, em que as mulheres possam encontrar atendimento integral e respaldo legal. Além disso, também há uma necessidade constante da avaliação do processo e do impacto das ações para corrigir e aprimorar o desempenho dessa rede de atendimento à mulher. ${ }^{5}$

\section{CONCLUSÕES}

Dentre os tipos de violência contra a mulher, no município da fronteira oeste do Rio Grande do Sul, foi identificada como a de maior prevalência, a violência doméstica cometida pelo parceiro íntimo, com idade entre 20 e 29 anos, atendida no pronto socorro, vítima de agressão de ordem física (espancamento), seguida de ferimentos de arma branca, com maior ocorrência nos finais de semana. E entre as morbidades destacaram-se as lesões cortantes, seguidas de encaminhamentos, dentre os mais relevantes, um a unidade de terapia Intensiva e um óbito.

Cabe ressaltar que a falta de registros adequados por parte dos profissionais de saúde podem ter limitado o levantamento dos dados sobre a identificação do agente agressor. Além das limitações associadas à característica do tipo de pesquisa, de delineamento documental, retrospectivo, fator esse limitador de uma leitura mais detalhada e aprofundada sobre a violência praticada contra a mulher a qual não se encontra tão bem especificada nas FAA, associado à própria complexidade da abordagem dessa temática.

Esse estudo também identificou a importância por parte dos profissionais de saúde de melhorar seu conhecimento em relação a esta temática a fim de aprimorar a busca e identificação das vítimas de violência seja ela de ordem física, psicológica ou sexual, bem como, atentar para a realização dos registros de casos de violência contra a mulher para que se possam obter números mais precisos sobre índice de violência no município melhorando a eficácia das políticas públicas de combate à violência contra a mulher.Assim como, esforços devem ser implantados, para que estudos desenvolvidos em áreas de 


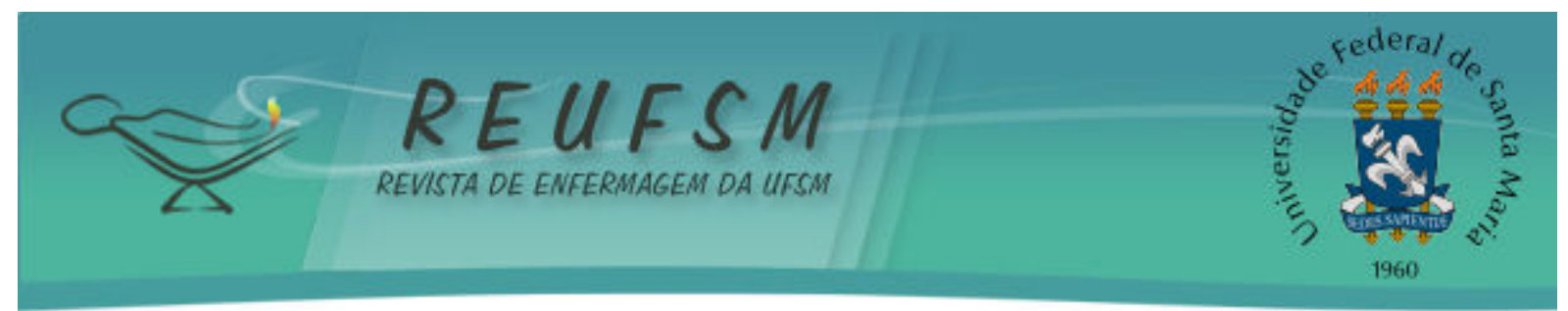

fronteiras, consideradas regiões vulneráveis sejam estimulados, pois ainda discussões acerca dessa temática encontram-se incipientes.

\section{REFERÊNCIAS}

1. Política Nacional de Redução da Morbimortalidade por Acidentes e Violência. Rev Saúde Pública [Internet]. 2000 ago [acesso em 2013 jul 28];34(4):427-30. Disponível em: http://www.scielo.br/scielo.php?script=sci_arttext\&pid=S0034-89102000000400020\&lng=en.

2. Organização Mundial da Saúde (OMS). Relatório mundial sobre violência e saúde. Genebra; 2002.

3. Costa MA, Rodrigues RN, Netto L, Santos J, Tatagiba GA. Formas de violência referidas no cotidiano escolar na percepção dos professores de uma escola pública. Rev Enferm UFSM [Internet]. 2013 maio [acesso em 2013 jul 28];3(1):44-52. Disponível em: http://cascavel.ufsm.br/revistas/ojs-2.2.2/index.php/reufsm/article/view/7605.

4. Vieira LB, Padoin SMM, Souza ÍEO, Paula CC. Perspectivas para o cuidado de enfermagem às mulheres que denunciam a violência vivida. Esc Anna Nery Rev Enferm. 2011;15(4):678-85.

5. Osis MJD, Duarte GA, Faúndes A. Violência entre usuárias de unidades de saúde: prevalência, perspectiva e conduta de gestores e profissionais. Rev Saúde Pública. 2012;46(2):351-8.

6. Okabe I, Fonseca RMGS. Violência contra a mulher: contribuições e limitações do sistema de informação. Rev Esc Enferm USP. 2009;43(2):453-8.

7. Villela WV, Vianna LAC, Lima LFP, Sala DCP, Vieira TF, Vieira ML, et al. Ambiguidades e contradições no atendimento de mulheres que sofrem violência. Saúde Soc. 2011;20(1):113-23.

8. Moraes AF, Ribeiro L. As políticas de combate à violência contra a mulher no Brasil e a "responsabilização" dos "homens autores de violência". Sexualidad, Salud y Sociedad. 2012;11:37-58.

9. Silva CD, Gomes VLO, Acosta DF, Barlem ELD, Fonseca AD. Epidemiologia da violência contra a mulher: características do agressor e do ato violento. Rev Enferm UFPE online. 2013;7(1):8-14.

10. Brasil. Lei 11.340, "Maria da Penha”, de 7 de agosto de 2006. Cria mecanismos para coibir a violência doméstica e familiar contra a mulher. Diário Oficial da União, Brasília; 2006 ago 8.

11. Brasil. Secretaria de Políticas para as Mulheres. Conheça a lei que protege as mulheres da violência doméstica e familiar. Brasília (DF); 2012. 40 p.

12. Brasil. Secretaria Especial de Políticas para as Mulheres. II Plano Nacional de Políticas para as Mulheres. Brasília (DF); 2008. 204 p.

13. Santos MA, Vieira EM. Recursos sociais para apoio às mulheres em situação de violência em Ribeirão Preto, SP, na perspectiva de informantes-chave. Interface (Botucatu). 2011;15(36):93-108.

14. Vieira LB, Padoin SMM, Souza ÍEO, Paula CC. Intencionalidades de mulheres que decidem denunciar situações de violência. Acta Paul Enferm. 2012;25(3):423-9.

15. Viellas EF, Gama SGN, Carvalho ML, Pinto LW. Fatores associados à agressão física em gestantes e os desfechos negativos no recém-nascido. J Pediatr (Rio J.). 2013;89(1):83-90. 


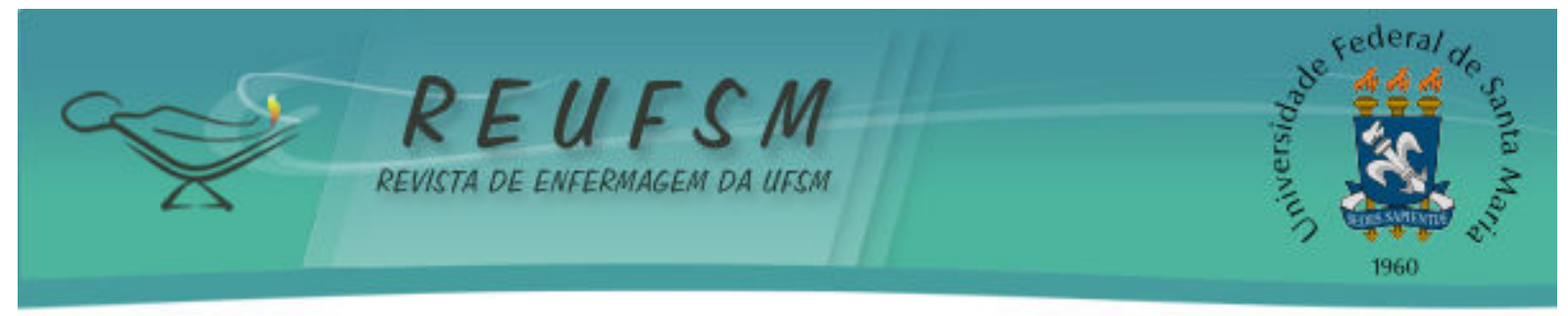

16. Castro JM, Rodrigues-Júnior AL. A influência da mortalidade por causas externas no desenvolvimento humano na Faixa de Fronteira brasileira. Cad Saúde Pública. 2012;28(1):195-200.

17. Brasil. Ministério da Saúde. Conselho Nacional de Saúde. Resolução n 466, de 12 de dezembro de 2012. Regulamenta pesquisas envolvendo seres humanos. Brasília (DF); 2012.

18. Cortez MB, Souza L, Queiróz SS de. Violência entre parceiros íntimos: uma análise relacional. Rev Psicol Polít. 2010;10(20):227-43.

19. Rodrigues CS, Malta DC, Godinho T, Mascarenhas MDM, Silva MMA, Silva RE. Acidentes e violências entre mulheres atendidas em Serviços de Emergência Sentinela - Brasil, 2009. Ciênc Saúde Coletiva. 2012;17(9):2319-29.

20. Vieira EM, Ford NJ, Ferrante FG, Almeida AM, Daltoso D, Santos MA. The response to gender violence among Brazilian health care professionals. Ciênc Saúde Coletiva. 2013;18(3):681-90.

21. Brasil. Ministério da Saúde. Sistema de Informação de Agravos de Notificação (SINAN). Portal da Saúde. [acesso em 2013 jul 22]; Disponível em: http://dtr2004.saude.gov.br/sinanweb/tabnet/dh?sinannet/violencia/bases/violebrnet.def

22. Belentani L, Sartorelli ACM, Meschial WC,Lima MF, Oliveira MLF. Violência contra crianças, adolescentes e mulheres: desfecho de casos atendidos em um hospital ensino. Rev Enferm UFSM [Internet]. 2012 abr [acesso em 2013 jul 28];2(1):10-9. Disponível em: http://cascavel.ufsm.br/revistas/ojs-2.2.2/index.php/reufsm/article/view/3944

23. Quadros MEF, Oliveira MM, Ferreira RZ, Alves PF. Violência doméstica: caracterização e atitude da equipe de saúde da família frente à problemática. Rev Enferm UFSM [Internet]. 2013 jul [acesso em 2013 jul 28];3(1):164-74. Disponível em: http://cascavel.ufsm.br/revistas/ojs2.2.2/index.php/reufsm/article/view/8359.

Data de recebimento: $18 / 10 / 2013$

Data de aceite: 04/02/2014

Contato com autor responsável: Marcia Adriana Poll

Endereço postal: Rua Iris Ferrari Valls, 1814, ap: 202 CEP:97500-340. Uruguaiana, RS, Brasil E-mail: adripoll@hotmail.com 